\title{
Estudo Prospectivo de Tecnologias para Cidades Inteligentes
}

\author{
Prospective Study of Smart Cities Technologies
}

\author{
Marcos Paulo Massao Iseki ${ }^{1}$ \\ Jeovan de Carvalho Figueiredo ${ }^{1}$ \\ ${ }^{1}$ Universidade Federal de Mato Grosso do Sul, Campo Grande, MS, Brasil
}

\begin{abstract}
Resumo
As Cidades Inteligentes podem ser entendidas como aquelas que utilizam as tecnologias de informação e comunicação baseadas em uma estrutura de rede com múltiplos propósitos. Tecnologias como essas podem ser exploradas por meio de informações patentárias. Assim, este trabalho objetiva caracterizar tecnologias de Cidades Inteligentes. Os resultados apontaram as tecnologias de redes de comunicação sem fio e os sistemas de controle de tráfego como mais frequentes. Um pequeno grupo de empresas são os maiores depositantes, sendo que os campos analisados possuem níveis de atratividade distintos, com predominância das tecnologias baseadas em redes de comunicação sem fio. Tais resultados permitiram avaliar potenciais ameaças e oportunidades para as organizações brasileiras que desenvolvem tecnologias nos campos tecnológicos analisados. Os resultados do estudo permitiram ainda análises comparativas entre instituições e países, gerando, assim, subsídios para melhorar a gestão de propriedade industrial $e$ as decisões sobre investimentos em Pesquisa e Desenvolvimento.
\end{abstract}

Palavras-chave: Prospecção Tecnológica. Patente. Classificação Internacional de Patentes (CIP).

\begin{abstract}
Smart Cities are those using information and communication technologies based on a multipurpose network structure. This kind of technology is available through patent information. Thus, this paper aims to characterize Smart City technologies. The results pointed to wireless communication network technologies and traffic control systems as the most recurrent technologies. A small group of companies is responsible for a significant part of patent fillings, and the fields analyzed have different levels of attractiveness, with a predominance of technologies based on wireless communication networks. These results allowed us to evaluate potential threats and opportunities for Brazilian organizations that develop technologies in the technological fields analyzed. The study results also allowed comparative analyzes between institutions and countries, thus generating subsidies to improve industrial property management and investment decisions in Research and Development.
\end{abstract}

Keywords: Technological Forecasting. Patent. International Patent Classification (IPC).

Área Tecnológica: Cidades Inteligentes. Redes de Comunicação sem Fio. Sistemas de Controle de Tráfego.

\section{Introdução}

O conceito de Cidades Inteligentes tem sido elaborado desde os anos 1990, evoluindo das primeiras menções a Cidades Digitais até as contemporâneas definições de Cidade Ubíqua, Cidade Sem Fio e Cidade Móvel (GRAHAM; AURIGI, 1997; ANTHOPOULOS; FITSILIS, 2014). 
Assim, ainda que a construção conceitual sobre o termo remeta a um período de mais de duas décadas, o conceito de cidade inteligente ainda continua em evolução (ANGELIDOU, 2015; CELLARY, 2013; ALBINO; BERARDI; DANGELICO, 2015; ANTHOPOULOS; FITSILIS, 2014).

Anthopoulos (2017) reuniu as propostas de outros autores para a elaboração de uma definição de Cidade Inteligente baseada em componentes predominantemente relacionados a infraestruturas de rede e protocolos de comunicação. Nessa definição, Cidade Inteligente é entendida como o espaço urbano que utiliza as Tecnologias de Informação e Comunicação (TICs) em proveito de aplicações relacionadas ao entorno, em sua gestão, nos seus serviços inteligentes, no tratamento de dados e nos seus negócios.

As aplicações, na definição proposta por Anthopoulos (2017), incluem mobilidade, governo, pessoas, modo de vida, economia e meio ambiente. A dimensão seguinte engloba a gestão do espaço urbano, dos processos, de pessoas, da informação e dos recursos municipais. A dimensão de serviços inteligentes, por sua vez, considera elementos como energia, água, resíduos, construção, turismo, educação, saúde, governo e transporte. Quanto à dimensão dados, compõem essa categoria aspectos como processos necessários ao tratamento e uso, originados a partir de documentos e pessoas, com abordagens em negócios e análises geoespaciais. Por fim, a dimensão negócios envolve aspectos como finanças, serviços, criatividade, produção e indústria.

A proposta de Anthopoulos (2017) é notadamente abrangente, mas aderente, em alguns aspectos, com os estudos de frequência de patentes de Pellicer et al. (2013) e de análise bibliométrica de Fu e Zhang (2017). Nesses estudos, dois aspectos tecnológicos são recorrentes e relacionados a cidades inteligentes, sendo eles: a) técnicas de comunicação elétrica; e b) mobilidade urbana.

Tais campos tecnológicos são identificados na Classificação Internacional de Patentes (CIP) na Subclasse H04W (inserida na Seção Eletricidade, na Classe de técnicas de comunicação elétrica e redes de comunicação sem fio) e na Subclasse G08G (pertencente à Seção de Física, na Classe de sinalização e sistemas de controle de tráfego). A Classificação G08G integra o Inventário de Tecnologias Verdes, conforme o IPC Green Inventory, mantido pela Convenção das Nações Unidas para as Mudanças Climáticas (INPI, 2018).

A Classificação Internacional de Patentes permite o uso de estatística de patentes na avaliação de atividades de inovação (PAVITT, 1985; NAGAOKA; MOTOHASHI; GOTO, 2010), na análise de correlações com o desenvolvimento econômico (GRILICHES, 1998; GOULD; GRUBEN, 1996) e no estudo do fluxo de conhecimento entre organizações a partir das patentes publicadas (FUNG; CHOW, 2002).

Hagedoorn e Cloodt (2003) estudaram a performance de inovação de 1.200 indústrias de alta tecnologia utilizando quatro indicadores: investimento em Pesquisa e Desenvolvimento (P\&D), contagem de patentes, citação de patentes e divulgação de novos produtos. A pesquisa concluiu que os indicadores podem ser usados para se avaliar o grau de inovação, principalmente no ramo da indústria de ponta.

Por sua vez, Rassenfosse et al. (2013) utilizaram uma forma de contagem de patentes prioritárias, aquelas depositadas em mais de um país, independentemente do escritório em que foi realizado o pedido. Segundo os autores, o indicador é útil na identificação de tecnologias emergentes e na análise de desempenho de economias em desenvolvimento (RASSENFOSSE et al., 2013). 
$\mathrm{Na}$ linha dos estudos relatados, este trabalho tem por objetivo caracterizar as tecnologias relacionadas a Cidades Inteligentes, com destaque para a análise dos requerentes mais atuantes na jurisdição internacional de registro de patentes.

Nas próximas seções, serão apresentados os procedimentos metodológicos, isto é, os passos para coleta e tratamento dos dados de pesquisa; em seguida, são discutidos os resultados obtidos; e, por fim, são apresentadas considerações decorrentes da análise dos resultados.

\section{Metodologia}

Para o alcance do objetivo proposto, foi elaborado um desenho de pesquisa que abrangeu seis etapas, conforme descrito no gráfico de fluxo apresentado na Figura 1.

Figura 1 - Etapas da pesquisa

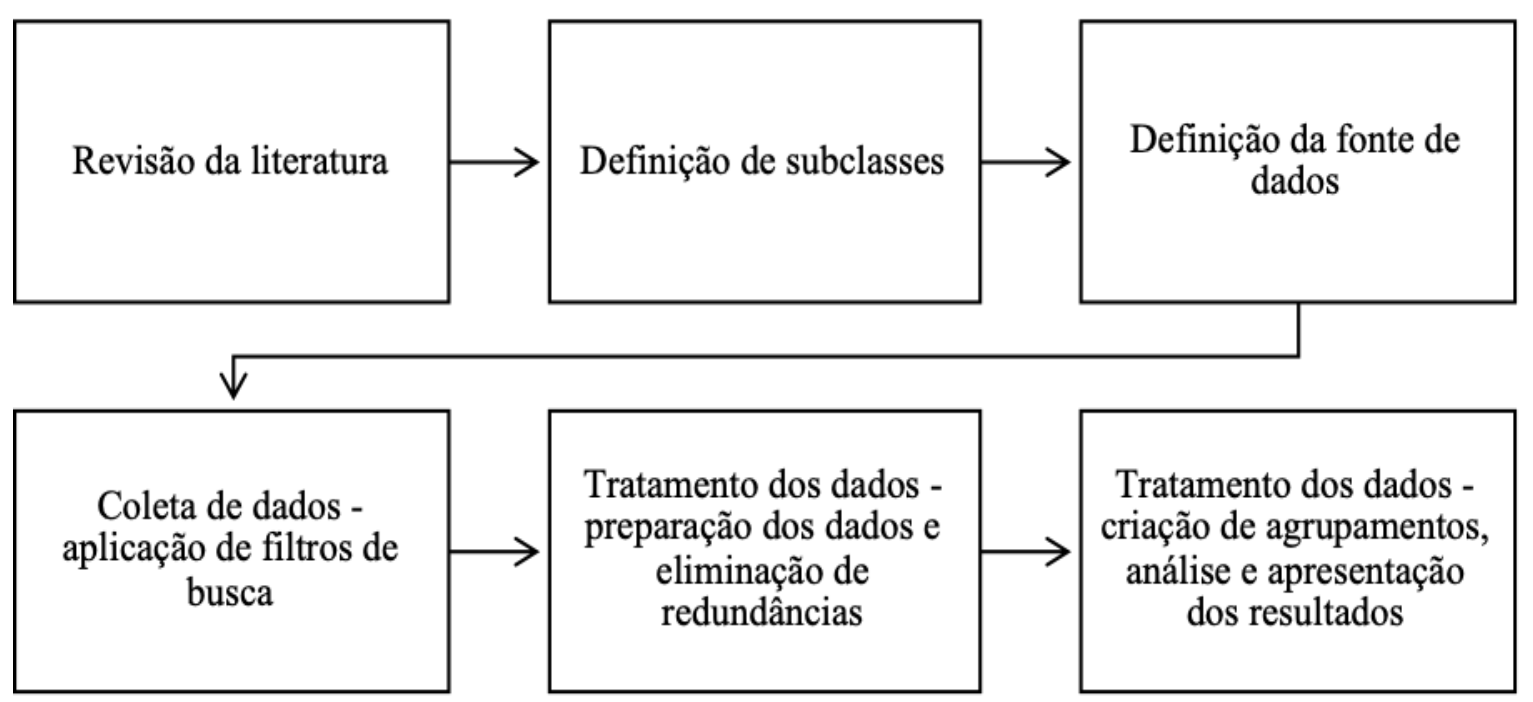

Fonte: Elaborada pelos autores deste artigo

A primeira etapa consistiu em revisão da literatura no Portal de Periódicos Capes, sendo utilizadas as palavras-chave "smart city" e patent e os filtros de artigos publicados em periódicos revisados por pares no período entre 2012 e 2018. Foram identificadas 132 ocorrências na data de realização da pesquisa (4/5/2019). Foi assim verificada a pertinência das Subclasses H04W e G08G para a análise pretendida neste estudo.

O passo seguinte foi definir a fonte dos dados. Krabbe, Sampson e Wetherbee (2017) avaliaram quatro ferramentas gratuitas de acesso a informações patentárias, comparando suas funcionalidades: Espacenet, Google Patents, PatentScope e Lens.org. Os aspectos analisados foram os relativos às funcionalidades e limitações gerais e aos destaques de cada sistema. Após a análise de vantagens e desvantagens, optou-se pela ferramenta Lens.org (www.lens.org) por ser a que reunia as melhores características para a presente pesquisa, entre elas, o agrupamento por família de patentes, recursos visuais e conjunto de variáveis de interesse em formato acessível para download.

Para a obtenção dos dados relevantes a esta pesquisa, foram aplicados os filtros de busca apresentados no Quadro 1. 
Quadro 1 - Filtros aplicados à busca das patentes

\begin{tabular}{|c|c|}
\hline CIPs selecionadas & $\begin{array}{ll}\cdot & \text { H04W } \\
\cdot & \text { G08G } \\
\cdot & \text { H04W AND G08G }\end{array}$ \\
\hline Período de tempo & - $1 / 1 / 2006$ a $31 / 12 / 2016$ \\
\hline Jurisdição & - WIPO - internacional \\
\hline Tipo de documento & $\begin{array}{l}\text { - Pedido de patente } \\
\text { - Patente concedida } \\
\text { - Certificado de proteção suplementar }\end{array}$ \\
\hline Língua & - Inglês \\
\hline Outras opções & $\begin{array}{l}\text { - Full text - texto completo } \\
\text { - Stemização - redução de palavras flexionadas }\end{array}$ \\
\hline
\end{tabular}

Fonte: Elaborado pelos autores deste artigo

Os procedimentos para tratamento dos dados foram baseados no Manual de Estatísticas de Patente da OECD (2009). Nesse estudo, foi incluído apenas o preparo dos dados em software de planilha. Assim, os arquivos exportados foram reunidos em um único arquivo com a quantidade total de ocorrências de pedidos de patentes das Subclasses H04W, G08G, e H04W AND G08G. No caso do agrupamento com intersecção (H04W AND G08G), o próprio filtro de busca do Lens.org excluiu as redundâncias com as subclasses independentes anteriores.

Foram organizados três agrupamentos de dados com base nas CIPs selecionadas (Grupo 1 - H04W, Grupo 2 - G08G e Grupo 3, compostos de ambas as CIPs). Foram excluídos os dados cuja variável Applicants estava vazia (variável nula).

O Microsoft Excel foi utilizado para a geração dos gráficos de frequência de depósitos de patente. Buscou-se nesse procedimento encontrar um agrupamento temporal que melhor representasse o desempenho tecnológico dos depositantes de patentes. O agrupamento escolhido foi por ano, pois partiu-se do pressuposto de que o ciclo que envolve a pesquisa, o desenvolvimento, os testes e o registro da patente são maiores do que um ano.

Os agrupamentos que fundamentaram a discussão apresentada na seção seguinte estão disponíveis para consulta no repositório Mendeley. O acesso pode ser feito a partir do link http:// dx.doi.org/10.17632/35ddwfw468.1

\section{Resultados e Discussão}

Aplicando os procedimentos descritos na seção anterior, a quantidade total de registros para a primeira busca, isto é, a CIP H04W, foi, inicialmente, de 80.569. Após a exclusão de cinco ocorrências que não informaram o nome do requerente, restaram 80.564 entradas válidas na CIP H04W. Para a segunda CIP (G08G), a quantidade foi de 7.309 registros. E no terceiro grupo (H04W AND G08G) foram identificados 352 registros. Esses dados foram estruturados na Tabela 1. 
Tabela 1 - Quantidade total de registros de patentes por CIP na jurisdição internacional (2006-2016)

\begin{tabular}{ccc} 
CIP & \multicolumn{2}{c}{ Frequência } \\
\cline { 2 - 3 } H04W & ABsoluta & Relativa (\%) \\
G08G & 80.564 & 91,32 \\
H04W AND G08G & 7.309 & 8,28 \\
Total & 352 & 0,40 \\
\hline
\end{tabular}

Fonte: Dados da pesquisa

Na sequência, a próxima análise de dados focalizou a variável Priority Numbers. O número de prioridade, tradução do termo, é um código identificador de registros de patentes no contexto do Tratado de Cooperação de Patentes (PCT). O número é constituído pela seguinte sequência: duas letras que identificam o código do escritório receptor, quatro dígitos numéricos referentes ao ano do pedido e um número sequencial variável composto de até sete dígitos.

Dessa forma, por meio do número de prioridade, foi possível traçar o perfil de nacionalidade do escritório receptor do pedido de patente para as CIPs H04W, G08G e H04W AND G08G. Na Figura 2, são apresentados os mapas de acordo com a CIP, entre os anos 2006 e 2016.

Figura 2 - Nacionalidade do escritório receptor por CIP (2006-2016)

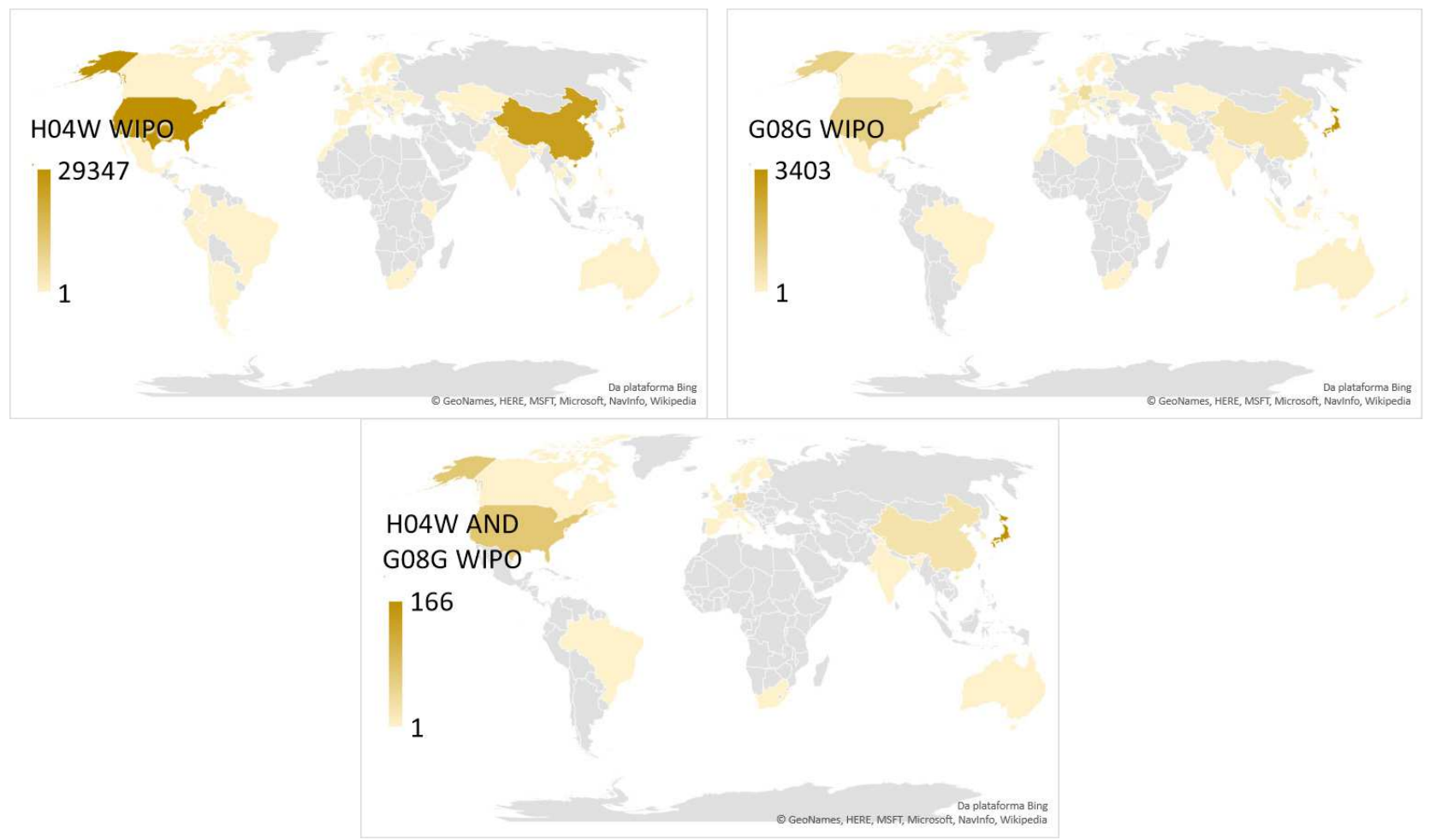

Fonte: Dados da pesquisa

Assim, no período analisado, isto é, entre os anos 2006 e 2016, para a CIP H04W, constatou-se que solicitantes oriundos dos Estados Unidos e da China responderam juntos por $67,43 \%$ dos registros, cenário em que solicitantes do Brasil correspondem a 0,05\% do total. 
No mesmo período, para a CIP G08G, requerentes que realizaram depósitos no escritório do Japão predominaram com 46,56\% dos registros, seguido pelos depósitos nos Estados Unidos $(15,79 \%)$ e na Alemanha $(10,59 \%)$. Os registros realizados no Brasil alcançaram apenas $0,19 \%$ do total.

Por último, para a CIP H04W AND G08G, o país que alcançou proporções expressivas foi o Japão, sendo responsável por $47,16 \%$ dos registros no período. Nesse contexto, os requerentes oriundos do escritório brasileiro foram responsáveis por $0,28 \%$ do total.

Na Tabela 2, são apresentados os percentuais de registros de patentes oriundos dos países com maior frequência de depósitos em relação à quantidade total protocolada entre os anos 2006 e 2016. Na tabela, é apresentada ainda a comparação dos depositantes com o número de registros feitos por organizações localizadas no Brasil.

Tabela 2 - Frequência de registros de patentes, por país e CIP (2006-2016)

\begin{tabular}{|c|c|c|c|}
\hline \multirow[t]{2}{*}{ CIP } & \multirow[t]{2}{*}{ País } & \multicolumn{2}{|c|}{ FrEQUÊNCIA } \\
\hline & & Absoluta & Relativa (\%) \\
\hline \multirow{6}{*}{ H04W } & Alemanha & 679 & 0,84 \\
\hline & Brasil & 37 & 0,05 \\
\hline & China & 24.985 & 31,01 \\
\hline & Estados Unidos & 29.344 & 36,42 \\
\hline & Japão & 9.126 & 11,33 \\
\hline & Outros & 16.393 & 20,35 \\
\hline TOTAL H04W & & 80.564 & 100,00 \\
\hline \multirow{6}{*}{ G08G } & Alemanha & 774 & 10,59 \\
\hline & Brasil & 14 & 0,19 \\
\hline & China & 464 & 6,35 \\
\hline & Estados Unidos & 1.154 & 15,79 \\
\hline & Japão & 3.403 & 46,56 \\
\hline & Outros & 1.500 & 20,52 \\
\hline TOTAL G08G & & 7.309 & 100,00 \\
\hline \multirow{6}{*}{ H04W AND G08G } & Alemanha & 30 & 8,52 \\
\hline & Brasil & 1 & 0,29 \\
\hline & China & 27 & 7,67 \\
\hline & Estados Unidos & 72 & 20,45 \\
\hline & Japão & 166 & 47,16 \\
\hline & Outros & 56 & 15,91 \\
\hline otal H04W AND G08G & & 352 & 100,00 \\
\hline
\end{tabular}

Fonte: Dados da pesquisa 
Assim, para a área de interesse de Cidades Inteligentes, notou-se que prevalecem pedidos oriundos dos Estados Unidos, do Japão, da China e da Alemanha. Tal dado possibilitou uma melhor compreensão do cenário tecnológico em foco.

Um outro dado revelado na Tabela 3 foi o baixo volume de requerimentos provenientes do escritório brasileiro no cenário internacional entre as CIPs relacionadas a Cidades Inteligentes.

Por sua vez, a Tabela 3 apresenta a frequência de registros de patente de requerentes brasileiros em cada CIP analisada. Na primeira linha da tabela, constam as frequências absoluta e relativa de requerentes brasileiros com apenas um registro de patente no período, isto é, sem recorrência na atividade. Já na segunda linha, as frequências de requerentes brasileiros com mais de um registro de patente.

Tabela 3 - Continuidade de registro de patentes por CIP (2006-2016)

\begin{tabular}{|c|c|c|c|c|c|c|}
\hline \multirow{2}{*}{ FREQUÊNCIA DE REQUERENTES BRASILEIROS } & \multicolumn{2}{|c|}{ H04W } & \multicolumn{2}{|c|}{ G08G } & \multicolumn{2}{|c|}{ H04W AND G08G } \\
\hline & ABs. & REL. (\%) & ABs. & REL. (\%) & ABs. & REL. (\%) \\
\hline Com apenas um registro & 27 & 84,38 & 9 & 81,82 & 1 & 100,00 \\
\hline Com mais de um registro & 5 & 15,62 & 2 & 18,18 & 0 & 0,00 \\
\hline TOTAL & 32 & 100,00 & 11 & 100,00 & 1 & 100,00 \\
\hline
\end{tabular}

Fonte: Dados da pesquisa

Verificou-se que, para as CIPs selecionadas, uma porcentagem significativa dos requerentes brasileiros realizou o registro de patente apenas uma vez no período estudado. A proporção de tal grupo variou de $81,82 \%$ para a CIP G08G na jurisdição internacional, chegando até $100 \%$ para a CIP H04W AND G08G, grupo em que nenhum requerente brasileiro registrou mais de um pedido de patente.

Contrastando com esse dado, na Tabela 4 verifica-se que houve requerentes cuja frequência contínua de registro de patentes alcançou a marca de 9.559 na jurisdição internacional da CIP H04W. A requerente em questão foi a multinacional chinesa Huawei Tech Co Ltd.

Tabela 4 - Registro de patentes por CIP e requerente (2006-2016)

\begin{tabular}{cccc} 
& ReQuerente & \multicolumn{2}{c}{ FrequêNCIA } \\
& & Abs. & Rel. (\%) \\
& Huawei Tech Co Ltd & 9.559 & 11,87 \\
H04W & Zte Corp & 8.377 & 10,40 \\
& Qualcomm Inc & 6.801 & 8,44 \\
& Ericsson Telefon Ab L M & 6.104 & 7,58 \\
& LG Electronics Inc & 3.837 & 4,76 \\
& Outras & 45.886 & 56,96 \\
& Subtotal H04W (A) & 80.564 & 100,00 \\
\hline
\end{tabular}




\begin{tabular}{|c|c|c|c|}
\hline & \multirow[t]{2}{*}{ REQUERENTE } & \multicolumn{2}{|c|}{ FREQUÊNCIA } \\
\hline & & Aвs. & REL. (\%) \\
\hline \multirow{7}{*}{ G08G } & Denso Corp & 246 & 3,37 \\
\hline & Nissan Motor & 412 & 5,64 \\
\hline & Bosch Gmbh Robert & 344 & 4,71 \\
\hline & Mitsubishi Electric Corp & 240 & 3,28 \\
\hline & Tomtom Int Bv & 110 & 1,50 \\
\hline & Outras & 5.957 & 81,50 \\
\hline & Subtotal G08G (B) & 7.309 & 100,00 \\
\hline \multirow{8}{*}{ H04W e G08G } & Denso Corp & 24 & 6,82 \\
\hline & Nec Corp & 21 & 5,97 \\
\hline & Bosch Gmbh Robert & 8 & 2,27 \\
\hline & Zte Corp & 7 & 1,99 \\
\hline & Huawei Tech Co Ltd & 6 & 1,70 \\
\hline & Outras & 286 & 81,25 \\
\hline & Subtotal H04W AND G08G (C) & 352 & 100,00 \\
\hline & Total $(A+B+C)$ & 88.225 & \\
\hline
\end{tabular}

Fonte: Dados da pesquisa

Além disso, os dados da Tabela 4 evidenciam que os cinco requerentes mais atuantes por CIP e jurisdição foram responsáveis por, no mínimo, 18,5\% do total de registros de patentes, na CIP H04W AND G08G.

Essa proporção alcançou os 43,04\% para a CIP H04W. Esses valores demonstraram que os campos tecnológicos relacionados a Cidades Inteligentes foram consistentemente explorados por um grupo de empresas multinacionais cuja composição variou pouco ao longo do tempo.

Essa evidência é corroborada pelas frequências anuais de depósito de patentes dos requerentes mais com maior volume de registros, em todas as CIPs estudadas. Como mostra a Tabela 5 , houve aumento no volume de solicitações de patentes nos campos analisados no período compreendido entre 2006 e 2016. 
Tabela 5 - Frequência anual de registro de patentes de requerentes mais atuantes, H04W, 2006-2016

\begin{tabular}{|c|c|c|c|c|c|c|c|c|c|c|c|c|}
\hline \multicolumn{13}{|c|}{ H04W } \\
\hline REQUERENTE & 2006 & 2007 & 2008 & 2009 & 2010 & 2011 & 2012 & 2013 & 2014 & 2015 & 2016 & TOTAL \\
\hline Huawei Tech Co Ltd & 220 & 424 & 396 & 703 & 496 & 825 & 1.261 & 1.638 & 1.394 & 1.321 & 881 & 9.559 \\
\hline Zte Corp & 72 & 139 & 99 & 511 & 1.617 & 1.458 & 981 & 748 & 895 & 917 & 940 & 8.377 \\
\hline Qualcomm Inc & 325 & 242 & 317 & 579 & 676 & 583 & 593 & 795 & 876 & 962 & 853 & 6.801 \\
\hline Ericsson Telefon Ab L M & 184 & 187 & 446 & 478 & 444 & 594 & 708 & 734 & 835 & 923 & 571 & 6.104 \\
\hline LG Electronics Inc & 50 & 80 & 57 & 259 & 379 & 535 & 316 & 424 & 459 & 610 & 668 & 3.837 \\
\hline $\begin{array}{l}\text { Freq. dos } \\
\text { requerentes (S) }\end{array}$ & 851 & 1.072 & 1.315 & 2.530 & 3.612 & 3.995 & 3.859 & 4.339 & 4.459 & 4.733 & 3.9133 & 34.678 \\
\hline Total & 2.323 & 3.763 & 3.810 & 6.536 & 7.784 & 8.853 & 8.734 & 9.858 & 9.535 & 9.991 & $9.377 \varepsilon$ & 80.564 \\
\hline Frequência relativa (\%) & 36,63 & 28,49 & 34,51 & 38,71 & 46,40 & 45,13 & 44,18 & 44,02 & 46,76 & 47,37 & 41,73 & 43,04 \\
\hline \multicolumn{13}{|c|}{ G08G } \\
\hline REQUERENTE & 2006 & 2007 & 2008 & 2009 & 2010 & 2011 & 12012 & 2013 & 32014 & 2015 & 52016 & 5 Total \\
\hline Denso Corp & 12 & 12 & 27 & 10 & 15 & 6 & 31 & 13 & 29 & 39 & 52 & 246 \\
\hline Nissan Motor & & 1 & 1 & 4 & 4 & 1 & 5 & 49 & 72 & 127 & 148 & 412 \\
\hline Bosch Gmbh Robert & 6 & 28 & 31 & 27 & 17 & 26 & 34 & 37 & 38 & 52 & 48 & 344 \\
\hline Mitsubishi Electric Corp & 1 & 4 & 1 & 4 & 3 & 3 & 26 & 72 & 40 & 65 & 21 & 240 \\
\hline Tomtom Int Bv & & 14 & 15 & 25 & 12 & 7 & 5 & 8 & 10 & 9 & 5 & 110 \\
\hline $\begin{array}{l}\text { Freq. dos } \\
\text { requerentes (S) }\end{array}$ & 19 & 59 & 75 & 70 & 51 & 43 & 101 & 179 & 189 & 292 & 274 & 1.352 \\
\hline Total & 298 & 591 & 543 & 532 & 488 & 556 & 553 & 713 & 766 & 1.043 & 31.226 & 67.309 \\
\hline Frequência relativa (\%) & 6,38 & 9,98 & 13,81 & 13,16 & 10,45 & 7,73 & 18,26 & 625,11 & 124,67 & 728,00 & 022,35 & 518,50 \\
\hline \multicolumn{13}{|c|}{ H04W AND G08G } \\
\hline REQUERENTE & 2006 & 2007 & 2008 & 2009 & 2010 & 2011 & 2012 & 2013 & 2014 & 2015 & 2016 & TOtal \\
\hline Denso Corp & & & 1 & 2 & 2 & 2 & 5 & 5 & 1 & 1 & 5 & 24 \\
\hline Nec Corp & & & & & & & & 4 & 5 & 4 & 8 & 21 \\
\hline Bosch Gmbh Robert & & & & & 1 & 1 & & & 1 & 3 & 2 & 8 \\
\hline Zte Corp & & & & & & & & 1 & & 5 & 1 & 7 \\
\hline Huawei Tech Co Ltd & & & & & & & & & 1 & & 5 & 6 \\
\hline $\begin{array}{l}\text { Freq. dos } \\
\text { requerentes (S) }\end{array}$ & 0 & 0 & 1 & 2 & 3 & 3 & 5 & 10 & 8 & 13 & 21 & 66 \\
\hline Total & 5 & 7 & 21 & 39 & 27 & 36 & 21 & 45 & 39 & 44 & 68 & 352 \\
\hline Frequência relativa (\%) & 0 & 0 & 4,76 & 5,13 & 11,11 & 8,33 & 23,81 & 22,22 & 20,51 & 29,55 & 30,88 & 18,75 \\
\hline
\end{tabular}

Fonte: Dados da pesquisa 
Em relação aos valores máximos e mínimos das frequências relativas registradas pelas requerentes mais atuantes, na CIP H04W, a maior frequência ocorreu em 2015, com 47,37\%, e a menor em 2007, com 28,49\%. Na CIP G08G, a maior frequência relativa aconteceu em 2015 , com $28 \%$ das patentes registradas, e menor frequência relativa em 2006 , com 6,38\%. E na CIP H04W AND G08G, o maior pico foi registrado em 2016, com 30,88\% e os valores mais baixos em 2006 e 2007, anos em que não houve registro de patentes pelas empresas listadas.

Assim, pela análise da frequência relativa, a importância de poucas organizações em relação às demais foi notória em todas as situações estudadas. Como mostra a Figura 3, mesmo quando analisada a frequência absoluta de depósitos, é possível observar o predomínio dos cinco maiores depositantes em cada uma das subclasses analisadas.

Figura 3 - Frequência anual de pedidos nas CIPs analisadas pedidos dos requerentes mais atuantes (2006-2016)

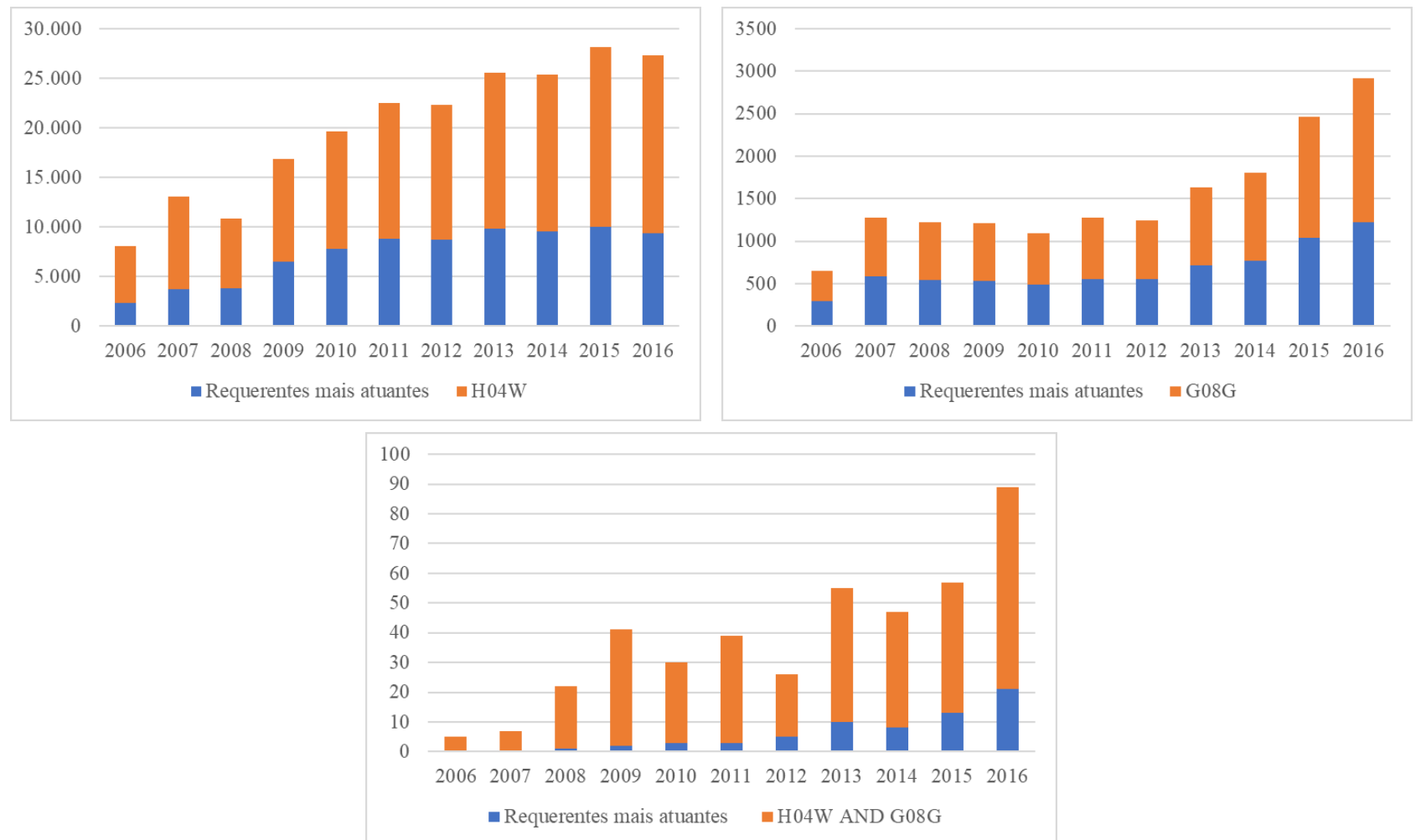

Fonte: Elaborada pelos autores deste artigo a partir dos dados da pesquisa

Conforme é possível ver pela Figura 3, verificou-se que as frequências totais de registros de patentes em cada CIP analisada, quando comparadas com aquelas dos cinco requerentes mais atuantes, mostram um quadro de predomínio que deve ser levado em consideração para a definição de estratégias tecnológicas e para a análise de investimentos em projetos com potencial de proteção de patentes.

Considerando os resultados apresentados nesta seção, ficam evidenciadas ameaças $e$ oportunidades para as organizações nacionais que almejam competir nos campos tecnológicos analisados no presente estudo. No que se refere a oportunidades, cabe destacar o reduzido número de pedidos de patentes encontrados na interface da CIP H04W, relacionada a técnicas de comunicação elétrica e comunicação sem fio, e da CIP G08G, relacionada à mobilidade urbana. Trabalhos como os de Pellicer et al. (2013), Anthopoulos (2017) e Fu e Zhang (2017) 
demonstram a associação de tais áreas como elemento constituinte de cidades inteligentes, residindo nessa intersecção eventuais oportunidades para o desenvolvimento tecnológico.

Contudo, existem ameaças também evidenciadas na presente análise. O ritmo do desenvolvimento tecnológico é acentuado em todos os campos analisados, e poucas organizações brasileiras puderam ser identificadas entre aquelas que reiteradamente avançam na fronteira dos campos tecnológicos analisados. A produção tecnológica pontual nesses campos indica que maior consistência pode ser necessária para alcançar as organizações que estão mais avançadas na fronteira tecnológica, exigindo técnicas de gestão para que os resultados sejam avaliados e, assim, percebidos tanto nas empresas quanto nos países nos quais estão localizadas (RASSENFOSSE et al., 2013).

\section{Considerações Finais}

Esta pesquisa objetivou caracterizar as tecnologias relacionadas a Cidades Inteligentes, com destaque para a análise dos requerentes mais atuantes na jurisdição internacional de registro de patentes. Verificou-se que, no período compreendido entre os anos de 2006 e 2016, 88.225 pedidos de patentes nas CIPs H04W (redes de comunicação sem fio), G08G (sistemas de controle de tráfego), além da intercessão das duas CIPs, isto é, H04W AND G08G.

Verificou-se também que os países mais atuantes na atividade de proteção patentária envolvendo tecnologias para Cidades Inteligentes foram a Alemanha, a China, os Estados Unidos e o Japão. Nesses países, há um pequeno número relativamente frequente de grandes multinacionais, corporações e conglomerados do ramo de eletrônicos e veículos terrestres e aéreos, que realiza parte significativa dos pedidos de proteção patentária ao longo do tempo.

Assim, a análise de países e requerentes evidenciou a atratividade mundial em relação aos campos tecnológicos estudados. Superar a concentração das maiores empresas depositantes e acelerar o ritmo do desenvolvimento tecnológico parecem ser os principais desafios para as organizações brasileiras que almejam gerar tecnologias para as cidades inteligentes.

Uma limitação do estudo consistiu na análise da distribuição geográfica da nacionalidade do escritório receptor, por CIP, pois não foi possível inserir na análise os registros de patentes realizados no escritório europeu. Tal procedimento se deve ao fato de que o escritório abrangia, no momento da coleta de dados, 38 países diferentes. Por não se tratar de uma nacionalidade específica, o software utilizado para gerar os mapas não oferecia suporte para associações de uma mesma patente a múltiplos países.

Ainda assim, os dados e resultados apresentados neste estudo podem ainda permitir análises comparativas entre organizações em tomadas de decisão a respeito de investimentos em pesquisa e desenvolvimento, além de delinear potenciais subsídios para políticas de gestão de propriedade industrial. 


\section{Referências}

ALBINO, V.; BERARDI, U.; DANGELICO, R. M. Smart cities: Definitions, dimensions, performance, and initiatives. Journal of Urban Technology, [s.l.], v. 22, n. 1, p. 3-21, 2015.

ANGELIDOU, M. Smart cities: a conjuncture of four forces. Cities, [s.l.], v. 47, p. 95-106, 2015.

ANTHOPOULOS, L. G. The rise of the smart city. In: Understanding Smart Cities: A Tool for Smart Government or an Industrial Trick? [s.l.]: Springer, Cham, p. 5-45, 2017.

ANTHOPOULOS, L. G.; FITSILIS, P. Smart cities and their roles in city competition: A classification. International Journal of Electronic Government Research (IJEGR), [s.l.], v. 10, n. 1, p. 63-77, 2014.

CELLARY, W. Smart governance for smart industries. Proceedings of the 7th International Conference on theory and practice of electronic governance. ACM, 2013. p. 91-93.

FU, Y.; ZHANG, X. Trajectory of urban sustainability concepts: A 35-year bibliometric analysis. Cities, Elsevier, v. 60, p. 113-123, 2017.

FUNG, M. K.; CHOW, W. W. Measuring the intensity of knowledge flow with patent statistics. Economics letters, Elsevier, v. 74, n. 3, p. 353-358, 2002.

GOULD, D. M.; GRUBEN, W. C. The role of intellectual property rights in economic growth. Journal of Development Economics, Elsevier, v. 48, n. 2, p. 323-350, 1996.

GRAHAM, S.; AURIGI, A. Urbanising cyberspace? The nature and potencial of the virtual cities movement. City, [s.l.], v. 2, n. 7, p. 18-39, 1997.

GRILICHES, Z. Patent statistics as economic indicators: a survey. R\&D and productivity: The Econometric Evidence, Chicago, University of Chicago Press, p. 287-343, 1998.

HAGEDOORN, J.; CLOODT, M. Measuring innovative performance: is there an advantage in using multiple indicators? Research Policy, [s.l.], v. 32, n. 8, p. 1.365-1.379, 2003.

INPI - INSTITUTO NACIONAL DA PROPRIEDADE INDUSTRIAL. Publicação IPC. 2018. Disponível em: http://ipc.inpi.gov.br/ipcpub/. Acesso em: 26 ago. 2018.

KRABBE, E.; SAMPSON, S.; WETHERBEE, I. Patent searching using free search tools. Intellectual Property Owner's Association, 2017.

NAGAOKA, S.; MOTOHASHI, K.; GOTO, A. Patent statistics as an innovation indicator. Handbook of the Economics of Innovation, [s.l.], Elsevier, v. 2, p. 1.083-1.127, 2010.

OECD - ORGANISATION FOR ECONOMIC CO-OPERATION AND DEVELOPMENT. Patent Statistics Manual 2009. [s.l.]: Organisation for Economic Co-operation and Development, 2009.

PAVITT, K. Patent statistics as indicators of innovative activities: possibilities and problems.

Scientometrics, Springer, v. 7, n. 1-2, p. 77-99, 1985.

PELLICER, S. et al. A global perspective of smart cities: A survey. In: PELLICER, S. et al. 2013

Seventh International Conference on Innovative Mobile and Internet Services in Ubiquitous Computing. IEEE, 2013. p. 439-444.

RASSENFOSSE, G. D. et al. The worldwide count of priority patents: A new indicator of inventive activity. Research Policy, [s.l.], v. 42, n. 3, p. 720-737, 2013. 


\section{Sobre os Autores}

\section{Marcos Paulo Massao Iseki}

E-mail:marcos.iseki@ufms.br Mestre em Administração Pública pela Universidade Federal de Mato Grosso do Sul em 2019.

Endereço profissional: UFMS - FACOM, Av. Costa e Silva, s/n, Cidade Universitária, Campo Grande, MS. CEP: 79070-900.

\section{Jeovan de Carvalho Figueiredo}

E-mail: jeovan.figueiredo@ufms.br

Doutor em Administração de Empresas pela Fundação Getúlio Vargas de São Paulo em 2009.

Endereço profissional: UFMS - ESAN, Av. Costa e Silva, s/n, Cidade Universitária, Campo Grande, MS. CEP: 79070-900. 